\title{
Dietary patterns in early childhood and child cognitive and psychomotor development: the Rhea mother-child cohort study in Crete
}

\author{
Vasiliki Leventakou ${ }^{1 *}$, Theano Roumeliotaki ${ }^{1}$, Katerina Sarri ${ }^{1}$, Katerina Koutra ${ }^{1}$, Mariza Kampouri ${ }^{1}$, \\ Andriani Kyriklaki ${ }^{1}$, Maria Vassilaki ${ }^{1}$, Manolis Kogevinas ${ }^{2,3}$ and Leda Chatzi ${ }^{1}$ \\ ${ }^{1}$ Department of Social Medicine, Faculty of Medicine, University of Crete, Heraklion, 71003, Crete, Greece \\ ${ }^{2}$ Centre for Research in Environmental Epidemiology (CREAL), Barcelona, E-08003, Spain \\ ${ }^{3}$ Municipal Institute of Medical Research (IMIM-Hospital del Mar), Barcelona, E-08003, Spain
}

(Submitted 13 June 2015 - Final revision received 22 December 2015 - Accepted 11 January 2016 - First published online 18 February 2016)

\section{Abstract}

Early-life nutrition is critical for optimal brain development; however, few studies have evaluated the impact of diet as a whole in early childhood on neurological development with inconsistent results. The present analysis is a cross-sectional study nested within an ongoing prospective birth cohort, the Rhea study, and aims to examine the association of dietary patterns with cognitive and psychomotor development in 804 preschool (mean age 4.2 years) children. Parents completed a validated FFQ, and dietary patterns were identified using principal component analysis. Child cognitive and psychomotor development was assessed by the McCarthy Scales of Children's Abilities (MSCA). Multivariable linear regression models were used to investigate the associations of dietary patterns with the MSCA scales. After adjustment for a large number of confounding factors, the 'Snacky' pattern (potatoes and other starchy roots, salty snacks, sugar products and eggs) was negatively associated with the scales of verbal ability $(\beta=-1 \cdot 31 ; 95 \% \mathrm{CI}-2 \cdot 47,-0 \cdot 16)$, general cognitive ability $(\beta=-1 \cdot 13 ; 95 \% \mathrm{CI}$ $-2 \cdot 25,-0.02)$ and cognitive functions of the posterior cortex $(\beta=-1.20 ; 95 \% \mathrm{CI}-2 \cdot 34,-0 \cdot 07)$. Further adjustment for maternal intelligence, folic acid supplementation and alcohol use during pregnancy attenuated the observed associations, but effect estimates remained at the same direction. The 'Western' and the 'Mediterranean' patterns were not associated with child neurodevelopmental scales. The present findings suggest that poorer food choices at preschool age characterised by foods high in fat, salt and sugar are associated with reduced scores in verbal and cognitive ability.

Key words: Dietary patterns: Cognition: Neurodevelopment: Preschool children: Birth cohort studies

Over the past few decades, several epidemiological and experimental animal studies have shown that early-life nutrition has a strong impact on cognitive development ${ }^{(1-3)}$. The existing literature, however, has mainly focused on nutrition in infancy and its association with cognitive and psychomotor development by highlighting the positive effect of prolonged breast-feeding ${ }^{(4-7)}$.

Early childhood is an important period for the establishment of food preferences and dietary habits, laying the formation of adult eating habits ${ }^{(8,9)}$. Only a few studies to date have investigated the role of child diet as a whole on cognitive development ${ }^{(10-13)}$. Birth cohort studies in infants aged 6, 12, 15 and 24 months reported that those who followed the 'breast-feeding' and the 'home-made' pattern had increased intelligence quotient (IQ) scores at 4 and 8 years of age ${ }^{(10,11)}$. A cross-sectional study performed by Theodore et $a l^{(12)}$ observed that children with high consumption of breads and cereals and fish at 3,.5 and 7 years of age had higher IQ scores. Half of the children included in this study were born small for gestational age, and generalisability of the results to other populations is rather difficult. On the other hand, a 'processed' (high fat and sugar content) pattern of diet at 3 years of age was negatively associated with IQ assessed at 8.5 years of age in the ALSPAC cohort in the $\mathrm{UK}^{(13)}$. All previously mentioned studies have assessed dietary patterns with the use of principal component analysis (PCA), which is a population-specific method and cannot be extrapolated to other populations.

Data from large observational studies suggest that higher adherence to Mediterranean-type diets relates to better cognitive function and a reduced risk of dementia in adults; however, its association with child cognitive function remains poorly explored $^{(14,15)}$. In the 1990 , the Cretan population had higher life expectancy mainly attributed to their Cretan Mediterranean diet $^{(16)}$, but despite the well-recognised health benefits this type of diet has undergone many changes and has become more Westernised. Recent findings confirm this nutritional transition showing that nowadays Cretan children consume more snacks

Abbreviations: IQ, intelligence quotient; MSCA, McCarthy Scales of Children's Abilities; PCA, principal component analysis.

* Corresponding author: V. Leventakou, fax +30 281039 4606, email vicky.chem@gmail.com 
and dairy products and less cereals when compared with what their peers consumed 15 years ago ${ }^{(17)}$. The investigation of dietary patterns, instead of single foods and nutrients, will allow us to evaluate the current diet of Cretan children as a whole and examine which dietary patterns are associated with their neurodevelopment

In the present cross-sectional study, nested within an ongoing prospective birth cohort study, we aimed to examine for the first time the impact of children's dietary patterns, as obtained by PCA, on cognitive and psychomotor development at preschool age. To assess this association, we used a validated FFQ, as well as a valid and complete version of an age-appropriate psychometric test ${ }^{(18)}$, after controlling for several confounding and mediator factors.

\section{Methods}

\section{Study population}

The 'Rhea' study is an ongoing prospective birth cohort based in southern Greece, in the island of Crete. The population included in the study are women living in the prefecture of Heraklion, aged 16 years or above, with no communication handicap, who were pregnant during 2007-2008. Starting in February 2007, women in early pregnancy (before 15th week of gestation) were asked to participate in the study. They were contacted again at various times during pregnancy, at birth, at 8-10 weeks after delivery and for children's follow-up at 9 months, 18 months and at 4 years of age. The initial recruitment and the subsequent follow-ups of the mothers and their children have been approved by the Ethical Committee of the University Hospital of Heraklion (Crete, Greece). All participants provided written informed consent.

The present analysis is a cross-sectional study, nested within the Rhea cohort. During the 4-year follow-up of the children, we obtained dietary information for a total of 1081 children with the use of a validated $\mathrm{FFQ}^{(19)}$. Children who followed a specific diet for health purposes ( $n$ 20) were excluded from the analysis. During the same follow-up, cognitive and neuropsychological development was assessed for 925 children by means of the McCarthy Scales of Children's Abilities (MSCA) test. In total, twenty-six children with a neurodevelopmental disorder diagnosis or other diagnosed medical conditions (i.e. plagiocephalus, microcephalus, hydrocephalus and brain tumour) and/or incomplete examination were excluded. We also excluded twenty-five pairs of twins. In total, 804 singleton children with full information on dietary intake and neurodevelopmental assessment were included in the present analysis.

\section{Dietary assessment}

Dietary intake information was collected at the 4-year follow-up, using the 'Rhea 4-year follow-up FFQ', a validated semi-quantitative FFQ designed to assess habitual dietary intake in preschool children ${ }^{(19)}$. The FFQ was administered to primary caregivers by a well-trained dietitian through telephone interview. The questionnaire included questions on 118 food items with the following components: food frequency, type of meals during the day (breakfast, morning snack, lunch, afternoon snack, dinner, evening snack), use of dietary supplements, type of fat used for cooking, frequency of meals consumed in restaurants or take away and television viewing during meals). Parents could select the portion size and report their child's intake in terms of frequency (times per day, week, month, year). Seasonality of consumption was also reported for food items. Daily intake of foods and nutrients was calculated using the UK food tables (McCance E Widdowson's The Composition of Foods, 6th summary edition) and standard Greek recipes (Composition Tables of Foods and Greek Dishes by Antonia Trichopoulou, 3rd edition) for complex mixed dishes. The dietary intake data were analysed by using a software program developed at the Department of Applied Information Technology and Multimedia, TEI-Crete, Heraklion, Crete, Greece.

Three dietary patterns were determined with the use of PCA: the 'Mediterranean', 'Snacky' and 'Western' dietary patterns ${ }^{(20)}$. The online Supplementary Table S1 describes the foods included in each pattern and their factor loadings. The 'Mediterranean' pattern was characterised by high intake of vegetables, fruits, pulses, olive oil, fish and seafood. The 'Snacky' pattern was characterised by foods that require minimum preparation such as potatoes and other starchy roots, salty snacks, sugar preserves and confectionery and eggs. The 'Western' pattern comprised cereals and bakery products, cheese, lipids of animal and vegetable origin, sweetened beverages (soft drinks, packed fruit juices) and meat products.

\section{Assessment of neurodevelopment}

Children's neurodevelopment was assessed at the 4-year follow-up, by two trained psychologists, with the ageappropriate instrument MSCA, developed for children aged $2 \cdot 5-8.5$ years. In brief, the MSCA test aims to identify possible developmental delay in different skills with the use of six scales: the verbal scale, the perceptual-performance scale, the quantitative scale, the general cognitive scale, the memory and the motor scale ${ }^{(18)}$. Each child received a score for every scale based on its performance, and at the end of the neurodevelopmental assessment the examiners evaluated the 'quality of assessment'. For each scale, the child's score was determined by the number of items for which credit was received. Raw scores on the separate scales of MSCA can range from 22 to 78 and on the general cognitive scale from 50 to 150 points. Executive function and cognitive functions of posterior cortex are two additional scales derived from the MSCA test ${ }^{(21,22)}$.

Raw scores of the neurodevelopmental assessment scales were standardised for child's age at test administration using a method for the estimation of age-specific reference intervals based on fractional polynomials ${ }^{(23)}$. Standardised residuals were then typified having a mean of 100 points with a $15 \mathrm{SD}$ to homogenise the scales as commonly used in studies evaluating neurodevelopment such as IQ assessment.

\section{Potential confounders}

Maternal and child socio-demographic and lifestyle characteristics were obtained via face-to-face or self-administered 
questionnaires and medical records from early pregnancy up to children's 4 years of age (4-year follow-up). Maternal education (low level: $\leq 6$ years of school, medium level: 7-12 years of school, high level: university or technical college degree) and maternal age were available at recruitment and were updated during the 4-year follow-up. Maternal folic acid supplement use (mg/week) and alcohol intake (g of alcohol/d) during pregnancy were collected at the second trimester of pregnancy. At birth, we collected details on child's sex (male/female), birth order (only child/first child/other), birth weight $(\mathrm{kg})$ and preterm birth $(<37$ weeks of gestation; yes/no). Breast-feeding duration (months) was reported for children at two time points: 9 and 18 months. Birth weight $z$-scores were adjusted for gestational age and sex. During the 4-year follow-up, we collected information on maternal residence (urban, rural), maternal working status (yes/no), marital status (marriedengaged/other), pre-school attendance (yes/no), passive smoking at home (yes/no) and $\mathrm{h} / \mathrm{d}$ spent watching television (almost never, 1, $\geq 2$ ). Maternal intelligence was measured using the Raven's Standard Progressive Matrices test ${ }^{(24)}$. Raven's test is a non-verbal test and the only self-administered test in the present analysis, in which the mothers were asked to answer sixty multiple choice questions, listed in order of difficulty. In each test item, they were asked to identify the missing element that completes a pattern. It is designed to measure reasoning ability, the eductive component of general intelligence.

\section{Statistical analysis}

In the present analysis, we used the DAFNE system for the classification of foods adapted to the Greek population ${ }^{(25)}$. The PCA method was used to reduce the data from the child's daily intake $(\mathrm{g})$ of the seventeen food groups and to identify the dietary patterns. The Kaiser-Mayer-Olkin measure was calculated to evaluate the sample adequacy. To identify the number of components, we used the eigenvalue of $>1$ criterion, the visual representation by the scree plot $^{(26)}$ and the interpretability of the factor loadings. Varimax rotation was applied to enhance the determination of the dietary components ${ }^{(27,28)}$. Factor loadings above 0.3 on a component were considered to have a strong association with that component. A score was attributed to every child for each of the components identified. The score was calculated for each of the components retained by summing the standardised values of the food items weighted by their scoring coefficients.

The possibility of nonlinear associations was tested by generalised additive models indicating linear relationships between children's dietary patterns and the neurodevelopmental outcome variables $(P>0 \cdot 1)$. Therefore, multivariable linear regression models were fitted to examine the associations after adjusting for confounders that modified any of the exposure coefficients by $10 \%$ or more. The 'quality of assessment', child's sex and examiner were included as a priori confounders in the present analysis. Estimated associations were described with $\beta$-coefficients and $95 \% \mathrm{CI}$.

We examined the role of confounders and potential modifiers in the association of dietary patterns with children's neurodevelopment at 4 years of age in six models presented in a chronological order: the first model (basic model) was adjusted for quality of assessment, child sex and examiner. The second model (confounding by infant characteristics) was adjusted for the variables in model 1 plus infant characteristics such as birth weight $z$-scores and breast-feeding duration. The third model (confounding by maternal characteristics) was adjusted for the variables in model 2 plus maternal characteristics including maternal age, maternal education, birth order and marital status. The fourth model (mediation by child life-style characteristics) was adjusted for the variables in model 3 plus child lifestyle characteristics such as day care attendance, passive smoking and hours per day spent watching television. The fifth model (confounding by maternal intelligence) was adjusted for variables in model 4 plus maternal intelligence. This model was performed for a subsample of the study population with available information on maternal intelligence $(n 339)$ as a sensitivity analysis. An additional sensitivity analysis (model 6) was carried out by excluding preterm births described by the sixth model (mediation by preterm birth) that was adjusted for variables in model 4 , after excluding preterm births ( $n$ 630). We also performed further adjustment for folic acid supplementation and alcohol intake during pregnancy (model 7 ) for mother-child pairs with available information on these variables ( $n$ 569).

All hypothesis testing was conducted assuming a 0.05 significance level and a two-sided alternative hypothesis. Stata S.E. version 13 was used for the statistical analyses (StataCorp LP).

\section{Results}

A description of the population characteristics is presented in Table 1. The majority of mothers had Greek origin ( $n$ 751, 94.4\%), medium education ( $n$ 394, 51.4\%) and were married ( $n 783,98.0 \%$ ). A total of $412(51.2 \%)$ boys and 392 $(48.8 \%)$ girls participated in the present analysis, had a mean birth weight of 3.20 (SD 0.45$) \mathrm{kg}$ and were breast-fed for 4.12 (SD 4.31) months. Most of the children attended pre-school ( $n$ 685, 85.7\%), and almost half of them were exposed to passive smoking ( $n 371,46.3 \%$ ) at 4 years of age. A higher proportion of the mothers participating in the analysis breastfed their children longer $(P<0.001)$ and were of higher education $(P<0.001)$ as compared with the non-participants (online Supplementary Table S2). The distribution of the standardised neurodevelopmental scores are described in Table 2. The standardised mean scores in the McCarthy scales were approximately 100 (SD 15), ranging from 97.87 points for the motor ability scale to 98.31 for the memory scale.

Table 3 presents the multivariable associations between the three dietary patterns and MSCA scores at 4 years of age. In the minimally adjusted model, the 'Western' and the 'Snacky' dietary patterns were associated with lower scores in verbal, quantitative, general cognitive ability, memory, executive function and cognitive functions of posterior cortex scales. Most of these associations remained after additional adjustment for birth weight and breast-feeding duration (model 2). Further adjustment for maternal socio-demographic characteristics (model 3) attenuated the associations with the 'Western' dietary pattern, whereas the 'Snacky' pattern remained negatively 
Table 1. Descriptive characteristics of the study population (Mean values and standard deviations; numbers and percentages)

\begin{tabular}{|c|c|c|c|}
\hline & $n$ & & $\%$ \\
\hline \multicolumn{4}{|l|}{ Maternal characteristics } \\
\hline Maternal age (years) & 795 & & \\
\hline Mean & & 33.48 & \\
\hline SD & & 4.99 & \\
\hline \multicolumn{4}{|l|}{ Maternal origin } \\
\hline Greek & 751 & & 94.4 \\
\hline Non-Greek & 45 & & $5 \cdot 6$ \\
\hline \multicolumn{4}{|l|}{ Maternal education } \\
\hline Low & 119 & & $15 \cdot 5$ \\
\hline Medium & 394 & & $51 \cdot 4$ \\
\hline High & 253 & & 33.0 \\
\hline \multicolumn{4}{|l|}{ Maternal working status } \\
\hline Working & 472 & & $59 \cdot 0$ \\
\hline Not working & 328 & & $41 \cdot 0$ \\
\hline \multicolumn{4}{|l|}{ Maternal marital status } \\
\hline Married & 783 & & 98.0 \\
\hline Other & 16 & & $2 \cdot 0$ \\
\hline \multicolumn{4}{|l|}{ Infant characteristics } \\
\hline \multicolumn{4}{|l|}{ Sex } \\
\hline Male & 412 & & $51 \cdot 2$ \\
\hline Female & 392 & & 48.8 \\
\hline \multicolumn{4}{|l|}{ Birth order } \\
\hline Only child & 147 & & 18.4 \\
\hline First child & 226 & & 28.3 \\
\hline Other & 426 & & $53 \cdot 3$ \\
\hline \multicolumn{4}{|l|}{ Preterm birth } \\
\hline Yes & 93 & & 11.9 \\
\hline No & 689 & & $88 \cdot 1$ \\
\hline Birth weight $(\mathrm{kg})$ & 779 & & \\
\hline Mean & & $3 \cdot 2$ & \\
\hline SD & & 0.45 & \\
\hline Breast-feeding duration (months) & 763 & & \\
\hline Mean & & $4 \cdot 1$ & \\
\hline SD & & $4 \cdot 31$ & \\
\hline \multicolumn{4}{|l|}{ Child characteristics at 4 years } \\
\hline \multicolumn{4}{|l|}{ Pre-school attendance } \\
\hline No & 114 & & $14 \cdot 3$ \\
\hline Yes & 685 & & $85 \cdot 7$ \\
\hline \multicolumn{4}{|l|}{ Passive smoking at home } \\
\hline No & 430 & & 53.7 \\
\hline Yes & 371 & & $46 \cdot 3$ \\
\hline \multicolumn{4}{|l|}{ Hours/day spent watching TV } \\
\hline Almost never & 218 & & $27 \cdot 3$ \\
\hline 1 & 298 & & 37.3 \\
\hline$\geq 2$ & 283 & & 35.4 \\
\hline
\end{tabular}

TV, television.

associated with child cognitive scores. A 1 sD increase in the 'Snacky' pattern score was associated with a 1.33 point decrease in the scale of verbal ability (95\% CI $-2 \cdot 49,-0 \cdot 17, P<0 \cdot 05), 1 \cdot 23$ point decrease in general cognitive ability $(95 \% \mathrm{CI}-2 \cdot 37,-0 \cdot 10$, $P<0.05)$ and 1.29 point decrease in cognitive functions of the posterior cortex $(95 \% \mathrm{CI}-2 \cdot 43,-0 \cdot 14, P<0 \cdot 05)$. Additional adjustment of child's lifestyle characteristics (model 4) did not attenuate the observed associations. We further adjusted for maternal intelligence (model 5) in a subsample of 339 motherchild pairs with available information on maternal cognition (Raven's test). We reduced model 4 to 339 mother-child pairs, and we observed that further adjustment for maternal intelligence did not change the direction of associations (data not shown). We also repeated our analysis after excluding preterm births, and results remained unchanged (model 6). When we further adjusted for folic acid supplementation and alcohol use
Table 2. Standardised scores of the McCarthy neurodevelopmental scales at 4 years of age (Mean values and standard deviations; $n$ 804)

\begin{tabular}{lcccc}
\hline Neurodevelopmental scales & Mean & SD & Minimum & Maximum \\
\hline Verbal ability & $98 \cdot 16$ & 16.56 & 48.85 & 148.08 \\
Perceptual performance & 98.26 & 15.86 & 43.82 & 146.72 \\
Quantitative ability & 98.06 & 16.38 & 46.19 & 151.39 \\
General cognitive ability & 97.94 & 16.47 & 43.97 & 143.91 \\
Memory & 98.31 & 16.29 & 56.79 & 150.48 \\
Motor ability & 97.87 & 17.00 & 26.94 & 147.95 \\
Executive function & 98.20 & 16.43 & 39.00 & 148.81 \\
Cognitive functions of posterior & 97.90 & 16.36 & 48.67 & 141.62 \\
$\quad$ cortex & & & & \\
\hline
\end{tabular}

during pregnancy, the 'Snacky' pattern remained negatively associated with all cognitive scales, although effect estimates were slightly attenuated.

\section{Discussion}

In the present analysis, we found that children who had unhealthy food choices at preschool age, characterised by processed and high-sugar foods, scored lower in verbal ability, general cognitive ability and cognitive functions of the posterior cortex. These associations persisted after the sequential adjustment of several socio-demographic and lifestyle factors. Further adjustment for maternal intelligence, folic acid supplementation and alcohol use during pregnancy in a subsample of the study population attenuated the observed associations, but effect estimates remained in the same direction. Findings from the present study add to existing literature by supporting weak but novel associations between dietary patterns and neurodevelopment in early childhood.

Comparison with other studies is rather complex mainly because of different methodological approaches including study design, food variability across countries, control of confounding factors and use of valid psychometric tests. However, these results are in line with two other cohort studies, which reported lower IQ scores for children who adhere to less healthy patterns, characterised by products high in fat and sugar ${ }^{(11,13)}$. Similar to our findings, these studies reported stronger associations in minimally adjusted models, but results attenuated after adjusting for a large array of confounders. The 'Snacky' and 'Western' dietary patterns in our analysis share some common food items. Both dietary patterns were negatively associated with child cognitive scores at the minimally adjusted models; however, effects remained significant only for the 'Snacky' pattern in the fully adjusted models. This could be possibly attributed to the lower variance explained by the 'Western' pattern (8.68\%) compared with the 'Snacky' pattern $(10.55 \%)$. Moreover, most of the food items included in the 'Western' pattern such as cereals and cereal products, meat and meat products and non-alcoholic beverages are commonly consumed by children at this age group.

The underlying mechanisms affecting verbal and cognitive child development because of poorer food choices characterised by higher intakes of fat and sugar at preschool age are rather complex. Animal studies have demonstrated detrimental 
Table 3. Multivariable associations between dietary patterns and neurodevelopmental test scores at 4 years of age in Rhea Cohort Study, Crete, Greece ( $\beta$-Coefficients and $95 \%$ confidence intervals)

\begin{tabular}{|c|c|c|c|c|c|c|c|c|c|c|c|c|c|c|c|c|}
\hline \multirow[b]{2}{*}{ Dietary patterns } & \multicolumn{2}{|c|}{ Verbal ability } & \multicolumn{2}{|c|}{$\begin{array}{l}\text { Perceptual } \\
\text { performance }\end{array}$} & \multicolumn{2}{|c|}{$\begin{array}{l}\text { Quantitative } \\
\text { ability }\end{array}$} & \multicolumn{2}{|c|}{$\begin{array}{c}\text { General } \\
\text { cognitive ability }\end{array}$} & \multicolumn{2}{|c|}{ Memory } & \multicolumn{2}{|c|}{ Motor ability } & \multicolumn{2}{|c|}{$\begin{array}{l}\text { Executive } \\
\text { function }\end{array}$} & \multicolumn{2}{|c|}{$\begin{array}{c}\text { Cognitive } \\
\text { functions of } \\
\text { posterior cortex }\end{array}$} \\
\hline & $\beta$ & $95 \% \mathrm{Cl}$ & $\beta$ & $95 \% \mathrm{Cl}$ & $\beta$ & $95 \% \mathrm{Cl}$ & $\beta$ & $95 \% \mathrm{Cl}$ & $\beta$ & $95 \% \mathrm{Cl}$ & $\beta$ & $95 \% \mathrm{Cl}$ & $\beta$ & $95 \% \mathrm{Cl}$ & $\beta$ & $95 \% \mathrm{Cl}$ \\
\hline \multicolumn{17}{|l|}{ Model $1 \dagger(n$ 804) } \\
\hline Mediterranean & -0.01 & $-1.04,1.02$ & -0.39 & $-1.41,0.64$ & -0.55 & $-1 \cdot 11,1.00$ & -0.21 & $-1.23,0.82$ & -0.16 & $-1.20,0.88$ & -0.79 & $-1.88,0.29$ & 0.04 & $-1.01,1.09$ & -0.42 & $-1.44,0.59$ \\
\hline Western & $-1.53^{\star \star}$ & $-2.59,-0.48$ & -0.10 & $-2.04,-0.06$ & $-1.63^{\star \star}$ & $-2.71,-0.55$ & $-1.61^{\star \star}$ & $-2.66,-0.57$ & $-1.60^{*}$ & $-2.66,-0.53$ & -1.01 & $-2.11,0.09$ & $-1.42^{*}$ & $-2.49,-0.35$ & $-1.53^{*}$ & $-2.57,-0.49$ \\
\hline Snacky & $-2 \cdot 62^{\star \star \star}$ & $-3.74,-1.51$ & $-2 \cdot 20^{\star \star *}$ & $-3 \cdot 31,-1 \cdot 09$ & $-1 \cdot 24^{*}$ & $-2 \cdot 39,-0.10$ & $-2 \cdot 60^{\star \star *}$ & $-3.70,-1 \cdot 49$ & $-1.82^{\star \star}$ & $-2 \cdot 95,-0.70$ & -0.69 & $-1 \cdot 85,0.48$ & $-2 \cdot 44^{\star \star \star}$ & $-3.57,-1.31$ & $-2 \cdot 42^{\star \star \star}$ & $-3.52,-1.33$ \\
\hline \multicolumn{17}{|l|}{ Model $2 \ddagger(n 754)$} \\
\hline Mediterranean & -0.34 & $-1.42,0.75$ & -0.46 & $-1.54,0.62$ & -0.26 & $-1.37,0.85$ & -0.49 & $-1.56,0.58$ & -0.45 & $-1.55,0.64$ & -0.82 & $-1.96,0.33$ & -0.29 & $-1.38,0.81$ & -0.63 & $-1.69,0.43$ \\
\hline Western & $-1 \cdot 19^{\star}$ & $-2.29,-0.09$ & 0.65 & $-1 \cdot 75,0.45$ & $-1 \cdot 25^{*}$ & $-2 \cdot 38,-0.12$ & $-1 \cdot 18^{\star}$ & $-2.27,-0.10$ & $-1 \cdot 35^{*}$ & $-2.45,-0.24$ & -0.63 & $-1.79,0.53$ & -1.04 & $-2.15,0.07$ & $-1 \cdot 11^{\star}$ & $-2.19,-0.03$ \\
\hline Snacky & $-2 \cdot 54^{\star \star \star}$ & $-3 \cdot 70,-1 \cdot 38$ & $-2 \cdot 38^{\star \star \star}$ & $-3 \cdot 53,-1 \cdot 22$ & -1.08 & $-2 \cdot 27,0.11$ & $-2.59^{\star \star \star}$ & $-3 \cdot 73,-1 \cdot 44$ & $-1.82^{\star \star}$ & $-2 \cdot 98,-0.65$ & -0.94 & $-2 \cdot 16,0.28$ & $-2 \cdot 34^{\star \star \star}$ & $-3.51,-1 \cdot 17$ & $-2 \cdot 50^{\star \star \star}$ & $-3 \cdot 64,-1 \cdot 36$ \\
\hline \multicolumn{17}{|l|}{ Model $3 \S$ ( $n$ 723) } \\
\hline Mediterranean & -0.06 & $-1.12,0.99$ & -0.60 & $-1.66,0.46$ & -0.11 & $-1.21,0.99$ & -0.35 & $-1.38,0.68$ & -0.21 & $-1.29,0.88$ & -0.78 & $-1.93,0.37$ & -0.18 & $-1.23,0.88$ & -0.49 & $-1.52,0.55$ \\
\hline Western & -0.66 & $-1 \cdot 73,0.41$ & -0.21 & $-1 \cdot 29,0.87$ & -0.72 & $-1 \cdot 84,0.40$ & -0.59 & $-1.64,0.46$ & -0.85 & $-1.95,0.26$ & -0.36 & $-1.54,0.81$ & -0.34 & $-1.41,0.73$ & -0.65 & $-1.71,0.41$ \\
\hline Snacky & $-1.33^{*}$ & $-2.49,-0.17$ & $-1 \cdot 16$ & $-2.33,0.01$ & -0.25 & $-1.46,0.96$ & $-1 \cdot 23^{*}$ & $-2.37,-0.10$ & -0.80 & $-1.99,0.39$ & -0.27 & $-1.54,1.00$ & -0.97 & $-2 \cdot 13,0 \cdot 18$ & $-1 \cdot 29^{*}$ & $-2.43,-0.14$ \\
\hline \multicolumn{17}{|l|}{ Model 4\|I ( $n$ 722) } \\
\hline $\begin{array}{l}\text { Mediterranean } \\
\text { Western }\end{array}$ & $\begin{array}{l}-0.17 \\
-0.40\end{array}$ & $\begin{array}{l}-1.22,0.88 \\
-1.48,0.67\end{array}$ & $\begin{array}{r}-0.85 \\
0.24\end{array}$ & $\begin{array}{l}-1.8 /, 0.19 \\
-0.82,1.31\end{array}$ & $\begin{array}{l}-0.36 \\
-0.31\end{array}$ & $\begin{array}{l}-1.44,0 . / 2 \\
-1.42,0.79\end{array}$ & $\begin{array}{l}-0.56 \\
-0.19\end{array}$ & $\begin{array}{l}-1.58,0.45 \\
-1.23,0.85\end{array}$ & $\begin{array}{l}-0.28 \\
-0.63\end{array}$ & $\begin{array}{l}-1.36,0.80 \\
-1.74,0.47\end{array}$ & $\begin{array}{l}-1.00 \\
-0.04\end{array}$ & $\begin{array}{l}-2.14,0.14 \\
-1.13,1.20\end{array}$ & $\begin{array}{r}-0.38 \\
0.06\end{array}$ & $\begin{array}{l}-1.42,0.65 \\
-0.99,1.12\end{array}$ & $\begin{array}{l}-0.68 \\
-0.29\end{array}$ & $\begin{array}{l}-1.71,0.35 \\
-1.340 .77\end{array}$ \\
\hline Snacky & $-1 \cdot 31^{*}$ & $-2.47,-0.16$ & -1.01 & $-2 \cdot 15,0.13$ & -0.12 & $-1.31,1.06$ & $-1 \cdot 13^{*}$ & $-2.25,-0.02$ & -0.82 & $-2.01,0.37$ & -0.13 & $-1.38,1.13$ & -0.87 & $-2.01,0.26$ & $-1 \cdot 20^{\star}$ & $-2.34-0.07$ \\
\hline \multicolumn{17}{|l|}{ Model $5 \uparrow$ ( $n$ 339) } \\
\hline Mediterranean & 0.47 & $-1.02,1.95$ & -0.69 & $-2.11,0.72$ & 0.35 & $-1.08,1 \cdot 77$ & -0.02 & $-1 \cdot 40,1 \cdot 40$ & 0.12 & $-1.37,1.60$ & -0.83 & $-2 \cdot 40,0 \cdot 76$ & 0.41 & $-1.04,1.86$ & -0.43 & $-1.80,0.95$ \\
\hline Western & 0.80 & $-0.87,2.48$ & 1.31 & $-2 \cdot 29,2 \cdot 90$ & 0.22 & $-1 \cdot 39,1.82$ & 1.13 & $-0.43,2 \cdot 70$ & 1.01 & $-0.66,2.69$ & 1.01 & $-0.78,2.79$ & $1 \cdot 1$ & $-0.51,2.75$ & 0.98 & $-0.57,2.53$ \\
\hline Snacky & -0.81 & $-2.52,0.90$ & 0.04 & $-1.58,1.67$ & 0.68 & $-0.96,2.32$ & -0.29 & $-1 \cdot 89,1 \cdot 30$ & -0.25 & $-1.98,1.46$ & 0.30 & $-1.52,2 \cdot 13$ & 0.16 & $-1.51,1.83$ & -0.63 & $-2.21,0.96$ \\
\hline \multicolumn{17}{|l|}{ Model $6+\dagger(n 630$} \\
\hline Mediterranean & 0.34 & $-0.81,1.49$ & -1.07 & $-2.23,0.09$ & -0.42 & $-1 \cdot 60,0.75$ & -0.38 & $-1.49,0.73$ & -0.05 & $-1 \cdot 24,1 \cdot 13$ & $-1 \cdot 00$ & $-2 \cdot 27,0.27$ & -0.23 & $-1.38,0.91$ & -0.47 & $-1.59,0.66$ \\
\hline Western & -0.46 & $-1.63,0.71$ & 0.10 & $-1 \cdot 08,1.28$ & -0.69 & $-1.89,0.50$ & -0.38 & $-1.51,0.75$ & -0.96 & $-2 \cdot 17,0.25$ & -0.03 & $-1 \cdot 32,1.27$ & -0.22 & $-1.39,0.94$ & -0.31 & $-1 \cdot 46,0.83$ \\
\hline \multirow{2}{*}{\multicolumn{17}{|c|}{ Model 7ł ( $n 569)$}} \\
\hline & & & & & & & & & & & & & & & & \\
\hline Mediterranean & -0.31 & $-1.55,0.92$ & -0.97 & $-2 \cdot 18,0.24$ & -0.46 & $-1.73,0.81$ & -0.70 & $-1.90,0.49$ & -0.31 & $-1.59,0.97$ & $-1 \cdot 39^{*}$ & $-2.73,-0.05$ & -0.40 & $-1 \cdot 61,0.81$ & -0.99 & $-2.21,0.23$ \\
\hline $\begin{array}{l}\text { Western } \\
\text { Snacky }\end{array}$ & $\begin{array}{l}-0.29 \\
-1.36^{*}\end{array}$ & $\begin{array}{l}-1.56,0.98 \\
-2.71,-0.01\end{array}$ & $\begin{array}{r}0.42 \\
-0.45\end{array}$ & $\begin{array}{l}-0.82,1.67 \\
-1.78,0.88\end{array}$ & $\begin{array}{l}-0.03 \\
-0.10\end{array}$ & $\begin{array}{l}-1.34,1.27 \\
-1.50,1.29\end{array}$ & $\begin{array}{r}0.02 \\
-0.93\end{array}$ & $\begin{array}{l}-1.21,1.24 \\
-2.24,0.38\end{array}$ & $\begin{array}{l}-0.41 \\
-0.76\end{array}$ & $\begin{array}{l}-1 \cdot 72,0.90 \\
-2 \cdot 16,0.64\end{array}$ & $\begin{array}{r}0.47 \\
-0.06\end{array}$ & $\begin{array}{l}-0.91,1.85 \\
-1.53,1.41\end{array}$ & $\begin{array}{r}0.09 \\
-0.80\end{array}$ & $\begin{array}{l}-1.15,1.34 \\
-2.13,0.52\end{array}$ & $\begin{array}{l}-0.10 \\
-0.85\end{array}$ & $\begin{array}{l}-1 \cdot 27,1 \cdot 25 \\
-2 \cdot 19,0.49\end{array}$ \\
\hline & & & & & & & & & & & & & & & & \\
\hline
\end{tabular}

TV, television.

$P<0.01,{ }^{* \star *} P<0.001$.

† Model 1: adjusted for quality of assessment, child sex and examiner.

¥ Model 2: plus birth weight $z$-scores, breast-feeding duration.

$\S$ Model 3: plus maternal age, maternal education, birth order, marital status.

II Model 4: plus day care attendance, passive smoking, TV watching.

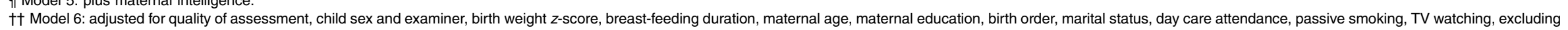
preterm births.

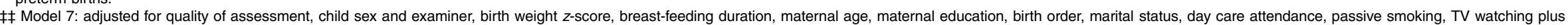
maternal folic acid and alcohol use during pregnancy. 
effects of a high-fat/high-cholesterol diet on cognitive performance in rats, associated with reduced hippocampal dendritic integrity and activation of microglial cells in the hippocampus ${ }^{(29)}$. Adult epidemiological studies have also shown that intake of a high-fat diet that includes mostly $n-6$ and SFA is associated with worse performance on cognitive tasks ${ }^{(30)}$. These associations may be even more profound at early life, as the brain grows at its fastest rate during the first 3 years of life, and it is possible that poorer food choices during this early period may discourage optimal head and brain growth ${ }^{(31)}$.

The associations seen with the 'Snacky' dietary pattern were stronger for verbal than for other cognitive scales (i.e. perceptual-performance and quantitative scales of MSCA). This is in line with the study by Northstone et $a l .{ }^{(13)}$ showing that a poor diet associated with high fat, sugar and processed food content in early childhood was associated with lower scores in verbal ability at 8 years of age. Although genetic and environmental influences on the development of general intelligence are well documented, less is known on the development of specific cognitive abilities (i.e. verbal $v$. non-verbal abilities), and the potential mechanism underlying the association of poor diet during early childhood with children's verbal abilities remain unclear. However, there is some evidence that shared family environmental factors are greater for verbal abilities than for non-verbal abilities, with the latter being related to individual's inherent mentality ${ }^{(32)}$.

Strengths of the present study include the assessment of children's diet with a validated dietary questionnaire, wellestablished outcome measures and control for several mother and child characteristics. Dietary patterns were determined with the use of PCA, which is a method that enables deep understanding of the diet as a whole, instead of isolated foods and nutrients, and thus promotes the design of valuable interventions and health policies. However, the PCA method introduces also researcher's subjectivity in the analysis, whereas dietary patterns derived from PCA are population-specific and therefore cannot be reproduced in other populations. Neurodevelopment assessment at preschool age was performed with the use of MCSA test, which is a valid psychometric test ${ }^{(18)}$; it provides both a general level of child's intellectual functioning and an assessment of separate neurodevelopmental domains (verbal ability, perceptual performance, number aptitude, memory, motor and executive functions), and thus detects which domain is mostly affected. We decided to exclude children with a neurodevelopmental disorder diagnosis, as neurological impairment in children is associated with an increased risk of feeding and nutritional problems. In the present analysis, we used standardised neurodevelopmental scales (mean of 100 points with a $15 \mathrm{SD}$ ). There is extensive literature on the public health impact of a 1-point loss of a neuropsychological scale; most of them are based on effects of lead exposure on $\mathrm{IQ}^{(33)}$. Although a seemingly small change of a 1-point decrease in IQ score might not be relevant at the individual level, at the population level this is possible to swift the distribution of IQ to the left and increase the number of persons below the normal range ${ }^{(34)}$. The inclusion of maternal intelligence, although available for a subsample of the total population, should be considered as an additional strength of the present study.
After adjustment for maternal intelligence, the direction of associations did not change in these models, compared with model 4 reduced to the subsample with available information. Significance levels were attenuated, probably because of small sample size available for this analysis or the possibility that maternal intelligence is associated with better food choices and thus with better child neurodevelopment.

The study has also some limitations. The cross-sectional design of the study does not permit the conclusion of any causal associations. Children included in the present analysis who had complete data were more socially advantaged than the remainder of the cohort, and this could lead to underestimation of the observed associations. Although we incorporated extensive information on potential social and environmental factors that are associated with child neurodevelopment, we acknowledge that residual confounding because of other unmeasured confounders such as home environment may still occur.

Overall, the present findings indicate weak but important associations between 'less healthy' dietary patterns, high in salty snacks, fat and sugar, and lower scores in verbal and cognitive ability scales for preschoolers. Public health implications of our findings highlight the importance of targeted nutritional policies or recommendations in order to promote early-life healthy dietary habits, before entry into formal education for optimal child cognitive and psychosocial development. Future research is needed to investigate the long-lasting effects of early life dietary patterns on child neurodevelopment in other populations or subgroups.

\section{Acknowledgements}

The authors would particularly like to thank all the cohort participants for their generous collaboration.

The Rhea study was financially supported by European projects (EU FP6-2003-Food-3-A NewGeneris, project no. 16320) (EU FP6 STREP Hiwate) (EU FP7 ENV.2007.1.2.2.2. Escape project no. 211250) (EU FP7-HEALTH-2009- single-stage CHICOS, project no. 241604), (EU FP7 ENV.2008.1.2.1.6. ENRIECO proposal no. 226285) and the Greek Ministry of Health (program of prevention of obesity and neurodevelopmental disorders in preschool children, in Heraklion district, Crete, Greece: 2011-2014; 349580).

All authors had a substantial contribution to the study and they have all reviewed and approved the submitted manuscript. Specifically, V. L. was the field study co-coordinator, participated in the statistical analysis and wrote the first draft of the paper; T. R. supervised the statistical analysis and helped with the data interpretation and manuscript preparation; K. S. participated in the design of the study and in the drafting of the paper; K. K. supervised the neurodevelopmental assessment and contributed to the drafting of the manuscript; M. K. and A. K. had the responsibility of the neurodevelopmental assessment and helped with data interpretation; M. V. provided feedback and critical revision of the manuscript; and M. K. and L. C. conceived the study, supervised the data collection, provided critical review of the manuscript and helped with data interpretation and manuscript preparation.

The authors declare that there are no conflicts of interest. 


\section{Supplementary material}

For supplementary material/s referred to in this article, please visit http://dx.doi.org/doi:10.1017/S0007114516000246

\section{References}

1. Smithers LG, Golley RK, Brazionis L, et al. (2011) Characterizing whole diets of young children from developed countries and the association between diet and health: a systematic review. Nutr Rev 69, 449-467.

2. Lucas A (1998) Programming by early nutrition: an experimental approach. J Nutr 128, 401S-406S.

3. Laus MF, Vales LD, Costa TM, et al. (2011) Early postnatal protein-calorie malnutrition and cognition: a review of human and animal studies. Int J Environ Res Public Health 8, 590-612.

4. Anderson JW, Johnstone BM \& Remley DT (1999) Breastfeeding and cognitive development: a meta-analysis. $\mathrm{Am} \mathrm{J}$ Clin Nutr 70, 525-535.

5. Leventakou V, Roumeliotaki T, Koutra K, et al. (2015) Breastfeeding duration and cognitive, language and motor development at 18 months of age: Rhea mother-child cohort in Crete, Greece. J Epidemiol Community Health 69, 232-239.

6. Bernard JY, De Agostini M, Forhan A, et al. (2013) Breastfeeding duration and cognitive development at 2 and 3 years of age in the EDEN mother-child cohort. J Pediatr 163, 36-42 e1.

7. Belfort MB, Rifas-Shiman SL, Kleinman KP, et al. (2013) Infant feeding and childhood cognition at ages 3 and 7 years: effects of breastfeeding duration and exclusivity. JAMA Pediatr 167, 836-844.

8. Ventura AK \& Worobey J (2013) Early influences on the development of food preferences. Curr Biol 23, R401-R408.

9. Birch L, Savage JS \& Ventura A (2007) Influences on the development of children's eating behaviours: from infancy to adolescence. Can J Diet Pract Res 68, s1-s56.

10. Gale CR, Martyn CN, Marriott LD, et al. (2009) Dietary patterns in infancy and cognitive and neuropsychological function in childhood. J Child Psychol Psychiatry 50, 816-823.

11. Smithers LG, Golley RK, Mittinty MN, et al. (2012) Dietary patterns at 6, 15 and 24 months of age are associated with IQ at 8 years of age. Eur J Epidemiol 27, 525-535.

12. Theodore FR, Thompsona JMD, Waldie KE, et al. (2009) Dietary patterns and intelligence in early and middle childhood. Intelligence 37, 506-513.

13. Northstone K, Joinson C, Emmett P, et al. (2012) Are dietary patterns in childhood associated with IQ at 8 years of age? A population-based cohort study. J Epidemiol Community Health 66, 624-628.

14. Lourida I, Soni M, Thompson-Coon J, et al. (2013) Mediterranean diet, cognitive function, and dementia: a systematic review. Epidemiology 24, 479-489.

15. Psaltopoulou T, Sergentanis TN, Panagiotakos DB, et al. (2013) Mediterranean diet, stroke, cognitive impairment, and depression: a meta-analysis. Ann Neurol 74, 580-591.

16. Renaud S, de Lorgeril M, Delaye J, et al. (1995) Cretan mediterranean diet for prevention of coronary heart disease. Am J Clin Nutr 61, 1360S-1367S.
17. Smpokos EA, Linardakis M, Sarri K, et al. (2013) Differences in food consumption according to weight status and physical activity levels among Greek children between 1992/93 and 2006/07. J Hum Nutr Diet 26, 259-267.

18. McCarthy D (editor) (1972) Manual for the McCarthy Scales of Children's Abilities. New York, NY: Psychological Corp.

19. Leventakou V, Georgiou V, Chatzi L, et al. (2014) Relative validity of an FFQ for pre-school children in the mother-child 'Rhea' birth cohort in Crete, Greece. Public Health Nutr 18 , 421-427.

20. Leventakou V, Sarri K, Georgiou V, et al. (2016) Early life determinants of dietary patterns in preschool children: Rhea mother-child cohort, Crete, Greece. Eur J Clin Nutr 70, 60-65.

21. Julvez J, Ribas-Fito N, Torrent M, et al. (2007) Maternal smoking habits and cognitive development of children at age 4 years in a population-based birth cohort. Int J Epidemiol $\mathbf{3 6}$, 825-832.

22. Barkley RA (2001) The executive functions and self-regulation: an evolutionary neuropsychological perspective. Neuropsychol Rev 11, 1-29.

23. Royston P \& Wright EM (1998) A method for estimating age-specific reference intervals ("normal ranges") based on fractional polynomials and exponential transformation. $J R$ Statist Soc 161, 79-101.

24. Raven JC \& Court JH (1996) Manual for Raven's Progressive Matrices and Vocabulary Scales. Oxford: Oxford Psychologists Press.

25. Lagiou P \& Trichopoulou A (2001) The DAFNE initiative: the methodology for assessing dietary patterns across Europe using household budget survey data. Public Health Nutr $\mathbf{4}$, 1135-1141.

26. Cattell RB (1966) The scree test for the number of factors. Multivariate Behav Res 1, 245-276.

27. Gorsuch RL (editor) (1974) Factor Analyses. Philadelphia, PA: W.B. Saunders.

28. Kline P (1994) An Easy Guide to Factor Analysis. London: Routledge.

29. Granholm AC, Bimonte-Nelson HA, Moore AB, et al. (2008) Effects of a saturated fat and high cholesterol diet on memory and hippocampal morphology in the middle-aged rat. J Alzheimers Dis 14, 133-145.

30. Freeman LR, Haley-Zitlin V, Rosenberger DS, et al. (2014) Damaging effects of a high-fat diet to the brain and cognition: a review of proposed mechanisms. Nutr Neurosci 17, 241-251.

31. Gale CR, O'Callaghan FJ, Godfrey KM, et al. (2004) Critical periods of brain growth and cognitive function in children. Brain 127, 321-329.

32. Kaufman A (editor) (1994) Intelligent Testing with the WISC-III. New York, NY: John Wiley \& Sons.

33. Grandjean P \& Landrigan PJ (2006) Developmental neurotoxicity of industrial chemicals. Lancet $\mathbf{3 6 8}$, $2167-2178$.

34. Rose G, Khaw KT \& Marmot M (2008) Rose's Strategy of Preventive Medicine: The Complete Original Text. New York, NY: Oxford University Press. 